\title{
A CASE STUDY ABOUT RFID TECHNOLOGY USAGE IN LIBRARY SERVICES
}

\author{
*Kenan AYDIN \\ **Seda YILDIRIM \\ *Yıldız Technical University, Turkey, \\ **Kocaeli University,Turkey
}

\begin{abstract}
Technology makes all kind of business' functions (such as manufacturing, finance, marketng, etc.) perform better. To survive in the competitive business environment, companies should resign their structure with new technologies. On the other hand, sectors which are not so competitive like as public library services, need to use new technologies to serve better. One of the new technology applications which has been being used in various sectors for 2000 years, is RFID technology. In this context, it was investigated how RFID technology was being used in library service with a case study in a concept of qualitative research method. For the case study, IRCICA library was chosen as a sample in İstanbul, Turkey. It was thought that IRCICA library was a suitable sample for this case study because of IRCICA library's historical development and functional attitudes. Data were collected by the way of interview, archival data and observation, and then they were analyzed according to their intended purpose. It is thought to be useful and pioneer for library services to develop their service process with RFID technology.
\end{abstract}

Keywords: RFID technology, RFID, library services

\section{INTRODUCTION}

The great usage of intelligent technologies such as wireless networks and Radio- Frequency Identification (RFID) (Kourouthanassis and Giaglis, 2005) has moved during the past decade from labs and niche areas into a broader range of application (Slettemeas, 2009) and has derived from the tremendous expansion in computing power and in data captured for decision-making in various domains of retailing, including inventory and supply chain management, category management, dynamic pricing, customer segmentation, etc.(Ravi et al.,2005:127). Extant literature shows that the usage of RFID technology is quite a new issue. Nevertheless, today, there are various areas in which RFID technology takes place. In this context, RFID has a wide variety of applications ranging from familiar building access control proximity cards to supply chain tracking, toll collection, parking access control, retail stock management, ski lift access, tracking library books, theft prevention, vehicle immobiliser systems and railway rolling stock identification, and movement tracking (Roberts, 2006:18). Lee \& Lee (2010) explained that RFID technology management was a process of evaluating RFID technology, developing RFID systems, managing RFID systems and RFID infrastructure to achieve business objectives.

Like as business sector, libraries have been using RFID technology since late 1990s (Ching and Tai, 2009; Topaloğlu, 2011). Hundreds of libraries in UK have implemented RFID for self-service and the vast majority of these libraries are positive about their RFID investment and its benefits. (Edwards and Fortune, 2008). Since traditional security systems was proved to be less effective, RFID has become a solution in time.

Due to being new technology, it has not been completely straightforward to research, purchase, or implement RFID technology. There is a big gap for RFID usage both in literature and in practice. In this context, the main purpose of this study was to determine whether RFID system was useful for a library or not. In addition, it was purposed to explain the historical development of RFID, the components of it and the main functions of it in library. 


\section{The Development of RFID Technology Usage in Libraries}

Today, technological developments have changed the working types of businesses. Radio Frequency Identification (RFID) technology is one of the emerging technologies that is being used by organizations such as manufacturers, retailers, logistics providers, hospitals, and libraries (Lee and Lee, 2009:313). Radio-Frequency Identification (RFID) technology can be defined as a wireless sensor technology which is based on the detection of electromagnetic signal (Domdouzis et. al., 2007:350).

RFID was first invented in 1948 and has subsequently undergone several developmental stages [4]. In the 1950s, the explorations of RFID technology were confined to laboratory experiments while the development of theory and field trials with RFID took place in the 1960s. The next decade saw an explosion in the development and testing of RFID technology(Hossain and Prybutok,2008:316). According to Hossain and Prybutok (2008) the commercial applications of RFID started in 1980s. RFID technology was used to tag livestock in order to track and monitor the weillbeing of animals in 1980s. When General Motors began to use RFID tags in car frames, the first commercial application of RFID came through. In the 1990s, RFID technology entered into supply chain to manage production and distribution systems (Slettemeas, 2009:221). According to Ngai et. al (2008), American originated companies such as Wal-Mart, and European companies such as Metro and Tesco have caused other companies to take a great attention for what RFID could do for them and they started to think whether they should give further consideration for adaptation(Ngai et.al.,2006:510).

Currently, RFID technologies are used to identify, capture, and transmit information from tagged objects to enterprise systems (Bhattacharya et. al.,2010:80). With these functions, RFID technology became popular for finding, counting and detecting items in retail sector and others. Thanks to some implementations also it was seen that RFID technology could be used in library circulation operations and theft detection in a security system (Boss,2004). Roh et. al.(2009) studied about RFID adaption in some organization and they explained RFID usage in libraries with a case study. They found out that more than 300 libraries in the United States had implemented RFID technology by 2003. This showed that these libraries had some benefits from RFID technology. According to the reports of the implementation, it was seen that the libraries which used RFID technology made their tracking, identifying and controling system more efficient(Roh et.al.,2009).

RFID can provide many benefits for libraries, therefore it becomes an inevitable technology in libraries, both for financial and human-related reasons(Schneider,2003:1). RFID system works similar with barcode system. Many libraries have already installed barcode systems where a barcode has been placed in each book and the LMS (Library Management System) uniquely identifies the book by reading the barcode, using a barcode scanner(Edwards and Fortune,2008:6). In other words, barcodes simplify the identification of items for library circulation and archives(Vasishta,2009:301). RFID system employs a specific reader use radio frequency to transmit information to multiple readings from or to the $\operatorname{tag}(\mathrm{Yu}, 2007: 57)$.

\section{The Components of RFID Technology in Libraries}

In general, RFID system has three basic components including a tag (transponder), a reader (transceiver), and a database (Slettemeas, 2009;Shoewu, O. and Badejo, O.,2006; Loebbecke, 2005). For libraries, RFID software programme should also be included as a component(Shahid,2005;Varma and Ahmed,2006;Sumi and Kumar,20007;Ching and Tai,2009). Radio frequency identification (RFID) is a small tag which contains an integrated chip and an antenna to send radio waves transmitted from the RFID reader in order to process, and then store information. The tag which is the key component of RFID(Loebbecke,2005) contains unique information ID of the item to which it is attached; the reader emits and receives radio waves to read the information stored in the tag, and the data-processing equipment processes all the collected data (Wu et. al., 2006:1317). However, it is very common to see transponders and tag antennas packaged as smartlabels (sealed RFID tags) consisting of an integrated circuit (IC) attached to an antenna in the shape of a coil of wires as in Figure 1. 


\section{Figure 1. RFID Reader and Tag Communication Flow Diagram}

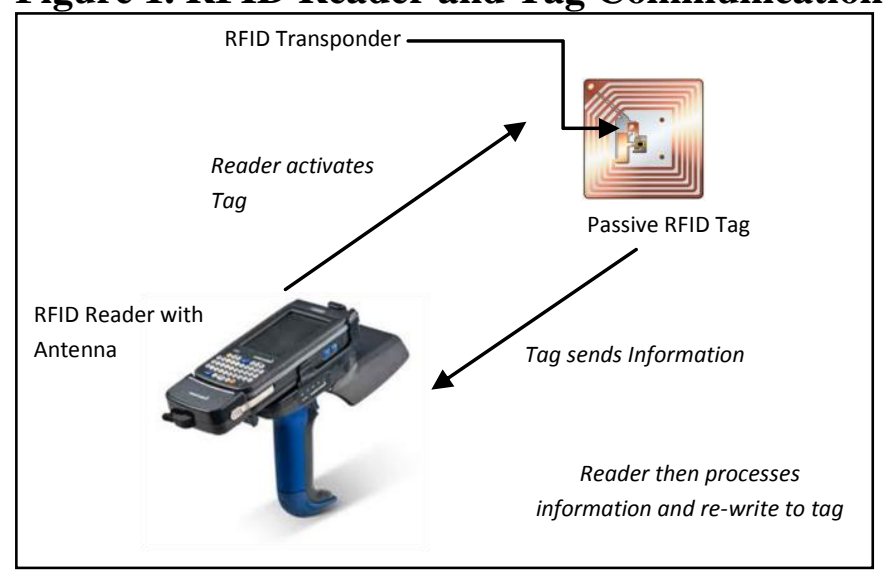

\section{Source: Aydın et.al.(2012), p.163}

RFID tag typically comprises a micro-chip and an antenna. The whole device (including the chip) is packaged with a paper-thin adhesive label which may be in a variety of shapes and sizes appropriate to the labelling of books, videos, DVDs and CDs etc. This can be applied to library resources in various ways to improve both stock management and security(Edwards and Fortune,2008:2). After sticking RFID label into the book, it's vital bibliographical data including unique accession number is registered in the chip of the label. This function allows writing such information on chip either from the library database or by scanning existing barcode labels and helps to identify each book (Vasishta,2009:302).

The reader sends out electromagnetic waves form a magnetic field when they join with the antenna on the RFID tag. The tag draws power from the magnetic field and uses it to power the microchip's circuits. Then the chip modulates the waves that the tag sends back to the reader and the reader converts the new waves into digital data. Data is stored in the tag chip in the form of an electronic product code (EPC)(Bottani and Rizzi,2008:548). It was showed how RFID system was working in usual in Figure 1. Same system works in libraries like other sectors or areas.

\section{The Frequency and Performance Situation of RFID Technology in Libraries}

Frequency allocations are managed through legislation and regulation by individual governments. Internationally, there are differences in frequencies allocated for RFID applications although there is standardization through ISO (International Organization for Standardization) and similar organisations which are assisting in compatibility. For example, the Europe uses $868 \mathrm{MHz}$ for UHF and the US uses $915 \mathrm{MHz}$. Currently, very few frequencies are consistently available for RFID applications, on a global basic(Roberts, 2006: 20). The frequency of transmitting information is a key factor in determining performance levels and applications for the system. Almostly, all RFID systems operate on one of four frequency bands: low frequency (LF), high frequency (HF), ultra high frequency (UHF), and microwave (MF) (Tajima, 2007: 262). 
Table 1: Operating Frequencies and Performance Characteristics

\begin{tabular}{|c|c|c|c|c|}
\hline & Low frequency $(\mathrm{LF})$ & High frequency (HF) & $\begin{array}{l}\text { Ultra high } \\
\text { frequency } \\
\text { (UHF) }\end{array}$ & $\begin{array}{l}\text { Microwave frequency } \\
\text { (MF) }\end{array}$ \\
\hline Frequency range & $125-134 \mathrm{Kz}$ & $13.56 \mathrm{Mz}$ & $860-930 \mathrm{MHz}$ & $2.45 \mathrm{GHz}$ \\
\hline Tag type & Passive & Mainly passive & $\begin{array}{l}\text { Active and } \\
\text { passive }\end{array}$ & Active and passive \\
\hline $\begin{array}{l}\text { Read } \\
\text { range(passive) }\end{array}$ & $<0.5 \mathrm{~m}$ & $1.0 \mathrm{~m}$ & $3.0 \mathrm{~m}$ & $10 \mathrm{~m}$ \\
\hline Tag size & Larger & Larger & Smaller & Smaller \\
\hline Data transfer rate & Slow & Medium & Fast & Fastest \\
\hline $\begin{array}{l}\text { Ability to read } \\
\text { near metal or wet } \\
\text { surface }\end{array}$ & Best & Better & Worse & Worst \\
\hline Tag cost & High & Lower than LF tags & Lowest & High \\
\hline $\begin{array}{l}\text { Typical } \\
\text { application }\end{array}$ & $\begin{array}{l}\text { Livetock tracking, } \\
\text { cardkey tracking, } \\
\text { Exxon Mobil } \\
\text { Speedpass }\end{array}$ & $\begin{array}{l}\text { Lower than LF tags } \\
\text { Airline baggage } \\
\text { handling, library book } \\
\text { tracking, electronic } \\
\text { article surveillance }\end{array}$ & $\begin{array}{l}\text { Supply chain } \\
\text { tracking, } \\
\text { warehouse } \\
\text { management }\end{array}$ & $\begin{array}{l}\text { Electronic toll collection, } \\
\text { Railroad monitoring }\end{array}$ \\
\hline
\end{tabular}

\section{Source: Tajima, Strategic value of RFID in supply chain management Journal of Purchasing\&Suppy Management 13(2007),261-263}

The most widely used RFID frequencies in today's applications are High Frequency (HF) and Ultra High Frequency (UHF). HF RFID systems operate at $13.56 \mathrm{MHz}$ and UHF RFID systems operate within the range from 860 to $960 \mathrm{MHz}$.(Ching and Tai,2009:348).

\section{Research Method}

This study used a qualitative research method to determine the benefits of using RFID technology in library services. With a case study, it was purposed to explain RFID technology usage in library services. It is believed that case studies are useful in the study of social sciences but they can not be considered as a suitable basis for generalization(Stake,1978:5). Case studies are in-depth investigations of a single person, group, event or community. Typically data are gathered from a variety of sources and by using several different methods (e.g. observations \& interviews). (Mcleod,2008). In this context, the case study method was preferred to determine the ways and benefits of using RFID in libraries. Interviews, archival data and observation technics were used to collect data for this study.

IRCICA library was chosen for the research in Istanbul, Turkey by purposive sampling method. The library was established at the Research Centre for Islamic History, Art and Culture (IRCICA) in 1980 with the aim of fulfilling the aims and functions of IRCICA. It is a reference library specialized in Islamic culture and civilization. It is one of the renowned special libraries in its field in the world. The selected and impressive collection of the library that consists of approximately 300.000 headings in 138 languages is placed on shelves of 3000 meters in length. The collection includes the followings: 60.000 books and rare works, 1460 titles of periodicals, 186 manuscripts, 1000 maps, 4000 offprints, 4000 grey literature, 300 microfilms and microfiches, photograph archives consisting of 70.000 historical photographs, OMETAR Archives comprising 150.000 items, IRCICA Activities Archives comprising 2580 documents, and Bammate Archives including 2150 documents. (http://library. ircica.org/default.aspx?@=AboutTheLibrary)

IRCICA library is the one among libraries which is using RFID technology in an active way. IRCICA library has been using new technologies since it was established. In 1983, IRCICA library was the first that had ever used library automation system (ILIS;IRCICA Library Informations System) (Topaloğlu,2011). According to the historical situations and functions of IRCICA library, it was thought that IRCICA was a right sample for this case study. 
Collected data included the results of both interview and observation. For interview, open-ended questions were prepared in a survey form. The questions included some special criteria to understand the ways and benefits of using RFID both for readers and library management. These criteria also set up according to the archival data. The basic questions were about:

1. The usage of RFID technology

2. The cost of RFID technology

3. Security with RFID technology

4. Counting performance with RFID technology

5. Finding books etc. in the library with RFID technology

6. Database system with RFID technology

7. Wrong-positioned book situation with RFID technology

8. Reaching the sources in the library with RFID technology

9. Library services as copyright and lending out books with RFID tchnology

With the questions based on above issues, researchers observed the library with a library worker to understand and see the RFID system at the library while it was working.

In September 2012, there had been an interview with the manager (A. Topaloğlu) and an observation in IRCICA library. Almost in 5 hours, the interview and the observation were finished. The collected data were allocated and analyzed according to the titles that were prepared as criteria.

- The usage of RFID technology: In general, UHF and HF RFID are used in library services(Ching and Tai,2009; Tajima,2007,Topaloğlu,2011). For instance, IRCICA library has been using UHF RFID system since 2008. A. Topaloğlu (the manager) explained how RFID system was working in IRCICA library with RFID's basic components and software programme. The software programme of BLISS made tag codes through MARC informations in IRCICA. UHF RFID tagging software programme was using bibliographical information to write codes on tags with RFID writer. Libraries have some standard categorization system and LC (Library of Congress) is the most common classification method. Books have specific ids which includes shelf id, category number, shelf number author number, title and publication date. It was seen that with RFID technology, the information about shelf ID, classification number, author's name, author's book first capital and publication date could be written on the book tag. After tags were coded, they were positioned in a book and the book was positioned on a shelf. The books that have tags on the shelves, could be seen on the library category system online.

- The cost of RFID technology: Although RFID is available as a technology for a long time, it is thought to be an expensive investment. On the other hand, the businesses which had set up RFID technology, got benefits and savings from some costs(Levy and Weitz,2003;Loebbecke, 2004; Lee and Lee, 2009; Aydın et. al.2012). UHF RFID system doesn't require to have so much money to be set up in libraries according to the manager (A. Topaloğlu). According to him, one library could set up UHF RFID system with approximately \$20.000-30.000. After this cost, the system did not require any high cost equipment of other things to keep going. Only tag cost could be existed and the cost of tags was about 0.22 cent which is a negligible amount for businesses. In addition, RFID technology has helped librarians reduce time loss occured by scanning barcodes while charging and discharging items (Varma and Ahmed, 2006:741). With this advantage, RFID technology has an ability to reduce labour-cost in libraries. When RFID system works in the library, the management doesn't need to have so many personnel in the library. For example, in IRCICA library, there has been only one personnel in the library to help readers and do other works after RFID system began. This case showed that libraries could have UHF RFID technology with a conceivable cost.

- Security with RFID technology: The most useful advantages of the RFID technology is thought to be used as a security performance (Coyle,2005). Boss (2004) explained the benefits of RFID technology usage in library and said that this system combined the tracking system with security system. In IRCICA library, the security system was the most developed system in the library. The old security door was just a symbolic door but now the new security door has a real security tool. With UHF RFID system, the readers were positioned in a library door to take signal form tags. The new door could control 4-5 meter area of the outside door easily. In addition, the new door 
could provide reporting the formal and informal information about book's movement during the controlling process. Although RFID could be used in library as an anti-theft system, this didn't mean that it was a highly secure technology (Coyle,2005). As Coyle(2005) explained, in this case, it was seen that RFID tags could be shielded by a thick layer of aluminum foil etc. so they would not be detected by the security system.

- Counting performance with RFID technology: The use of RFID definitely reduces the amount of time required for counting. The most significant time saving fact is that the information can be read from RFID tags much faster than from barcodes and several items in a stack can be read at the same time(Sumi and Kumar,2007:460). In IRCICA library, counting was performed by UHF RFID technology faster and easlier than before. According to the manager, counting could be done with a portable handheld reader with only one person in 4-5 hours a day. The portable handheld reader could be moved along the items on the shelves without touching them. The data went to a storage unit, which could be downloaded at a server later on, or it could go to a unit, which would transmit it to the server using wireless technology (Varma and Ahmed,2006; Topaloğlu,2011). During the counting process, readers could use books or library at the same time. In the past, IRCICA library was closed when there was a counting operation and this operation couldn't be finished before one or two days.

- Finding books etc. in the library with RFID technology: In libraries, RFID system scans books on the shelves without tipping them out or removing them. The portable handheld reader can be moved rapidly across a shelf of books to read all of the unique identification information (Sumi and Kumar,2007:461). With this advantage, finding book or another source which is tagged in RFID system, is easier than before. In IRCICA library, the management is so pleased to use UHF RFID technology beacuse of finding books easily. The manager explained and showed how UHF RFID system worked in finding books in IRCICA. He told that readers could find what they want with a portable handheld reader with the software programme. At first, the book which was searched, was introduced to the portable handheld reader. Then the portable handheld reader scanned the shelves from $20 \mathrm{~cm}-30 \mathrm{~cm}$ distance. While the shelf was scanning, the portable handheld reader gave some sound as an alarm. Lastly, the most soundly alarm came when the handheld reader found the right book.

- Database system with RFID technology: In libraries, RFID system needs a software programme to make a great database for libraries. In IRCICA library, the management could make reader's profile, could follow the book's movement, could see the reader's situation that the library could make reports with the statistical data. According to the manager, RFID's software system has had lots of benefits for library. He said that IRCICA library made reports about reader's profile regularly and design library inside to serve better. With this, IRCICA library has been managing their collection better since it began to use UHF RFID system. Every information about library services could be seen at the database in IRCICA library. Add to this, IRCICA library has had better controlling system.

- Wrong-positioned book situation with RFID technology: Libraries generally encounter the wrong-positioned book problem and readers complain about this situation. Wrong-positioned books reduce the efficiency of library and readers can't reach the sources when they are not available at the right time at the right place. At this point, UHF RFID system provides benefit with finding sources for the readers. People use the portable handheld reader and find the place of a book easily. As it was told before, the portable handheld reader give an alarm when it finds the right book. In a few minutes, readers or library staffs can find the book. It can be said that UHF RFID system find wrong-positioned books quickly and the management can organize sources better in a short time.

- Reaching the sources in the library with RFID technology: The readers who use IRCICA library, sometimes leave the books on the table and then forget which book they had before. In the past, in IRCICA library, nobody could find the book that the reader took and used before. After UHF RFID system, the management have been successful in finding books even they were positioned in a wrong shelf. If readers reach and use the sources which they need, it means that the library works efficiently. IRCICA library has been working much more efficiently. The readers are so pleased to find what they want quickly in IRCICA library. According to the manager, UHF 
RFID system has provided quick and reliable service in library. IRCICA library gave card to the reader and then the library could recognize the reader whenever he/she came to the library. IRCICA library could send e-mails or messages to the readers and the readers can learn their library information easily.

- Library services as copyright and lending out books with RFID technology: The readers of IRCICA library, usually want to take a copright from books. The copyright machine changed and began to work related with RFID software programme in IRCICA library. So now, the readers can get copyrights easilier and they can take the same copies whenever they come to the library. The new system records the copyright informations that the readers don't need to take the sources for a new copy, he/she can get the same one from the database. It is one of great advantages of UHF RFID system in library. In addition, every reader can see the copyright information from the web system in library. If there is a copy from the wanted sources, the readers don't need to find the real book, he/she can use the copy easily. The database of copyright has lots of information like shelf ID, classification number, author's name, pages of sources, users of these sources etc.

\section{CONCLUSION}

This study was designed to explain how RFID technology could be used in libraries and what were the benefits of using this technology. For this purpose, it was investigated with a case study in Istanbul, Turkey. Since being a case study in a quantitative method, this study provided information such as an exploratory research. Having included only one library (IRCICA library) as a sample was one of the limitations of this study.

It was given some titles about this case study to explain how RFID system was working in libraries. Since 2004, the libraries have been using RFID system to operate their service process in a more efficient way. On the other hand, this technology hasn't been widespread in general. One of the most deterrent subject about RFID technolgy is being too expensive. In fact, some areas such as retail warehouse and retail stores, the establishment cost of RFID system is still too high. In addition to this disadvantage, when the items (products) are purchased, the tags of them will be gone and the cost of tags will be always variable cost for businesses. But in library service sector, the establishment cost of RFID system is comprehensible enough to change traditional library system into more technological one. For example, in IRCICA library (case study sample), the cost of RFID system was about \$20.000-30.000 and then the cost of each tag was about 0.22 cent at total. The items of library always stayed in the library and so the cost of tags would not be variable cost for library. At this point some public sectors such as library, may have a great advantage in tag cost in general.

Security system in library changed into more efficient system in IRCICA library after the RFID technology was set up. According to the interview and observation, it was seen that the security door became a real guard tool for library. With an alarm factor, the thefts or other bad situations could be caught immediately and every situation could be recorded at the same time. The items which were taken without any permission by library, could be observed and followed with tag reader in a library area. The security function of RFID in libraries which is so useful as it was said in literature (Boss,2004;Schneider,2003;Coyle,2005) was also seen in this case study. On the other hand, the security system has some troubles to be perfect in practice. When someone used foil paper to get one kind of source in library, the system couldn't work efficiently. The readers couldn't see the frequencies when the tags were in some kind of foil paper.

In this case, it was also found out that RFID system provided both time and staff savings for libraries in operation. For example, there was an only one staff in IRCICA library and this staff could do everything easily. With the usage of portable handheld reader, IRCICA library could finish all kind of operations such as counting inventory, scanning books, finding books etc. in a short time. It was seen that data base system of RFID technology could provide copyright informations, the information of the reader's profile to the library management. When one reader took a copy of one book, later, another one could take the same copy form the library management without any effort to look this book in the shelves. In IRCICA library, readers could easily find their book with a portable handheld reader wherever they were in the library. After a reader used a book and took a copy from it, another reader or same one could take a copy from the same book without any effort to look for the book at 
the library. Because the copyright machine was connected with the RFID system in the library, every knowledge about book circulation and readers were recorded by database system time to time. This database also provided IRCICA library to evaluate reader's profile and manage the library collections better. When IRCICA library learned the reader's profile, it could design the collection according to this information. IRCICA library management told that they had started to redesign their collection for the most wanted books with RFID system.

To sum up, the main contribution of this case study was to explain how the RFID technology could be used in libraries. In addition to that, it was seen that there were several advances on RFID forms during the years for libraries like retailers or manufacturars. According to the results which contain both interview and observation, it could be said that RFID technology usage provided some benefits such as efficient security system, time-saving in item-circulation in library, staff reduction and espacially in counting inventory operation. It can be suggested to the libraries to install RFID system to perform better and satisfy the readers. 


\section{REFERENCES}

Aydın K.,Ustaahmetoğlu E., Yıldırım, S.(2012), "The Theoretical Framework For Usage Of Rfid Technology In Retail Sector”, ITAM 8 Conference, 28-30 June,2012, Y1ldız Technical University, Istanbul, Turkey).

Bhattacharya, M., Chu, C.H., Haya, J., Mullen, T.(2010), “An Exploratory Study Of RFID Adoption In The Retail", Oper Manag Res (2010) 3, pp.80-89.

Boss. R. W.(2004), “RFID Technology For Libraries”, PLA Tech Notes (May 14, 2004).

Bottani ,E., Rizzi, A.(2008), "Economical Assessment Of The Impact Of RFID Technology And EPC System On The Fast-Moving Consumer Goods Supply Chain”, Int. J. Production Economics, 112, pp.548-569 .

Chachra, V.(2003), "Experiences in Implementing the VTLS RFID Solution in a Multi-vendor Environment", World Library and Information Congress: 69th IFLA General Conference and Council, 1-9 August, Berlin.

Coyle, K.(2005), "Management Of RFID İn Libraries, Managing Technology”, The Journal of Academic Librarianship, Volume 31, Number 5, pp. 486-489.

Ching Steve H., Tai, A.(2009), "HF RFID Versus UHF RFID-Technology For Library Sevice Transformation At City University Of Hong Kong", The Journal of Academic Librarianship, Volume 35, Number 4, July, pp.347-359.

Domdouzis, K., Kumar, B., Anumba, C.(2007), "Radio-Frequency Identification(RFID) Applications: A Brief Introduction", Advanced Engineering Informatics, 21, pp.350-355.

Edwards, S., Fortune, M.(2008), “A Guide to RFID In Libraries”, Book Industry Communication,BIC e4libraries Project.

Hossain, M. M., Prybutok, V. R.(2008), “Consumer Acceptance of RFID Technology: An Exploratory Study”, IEEE Transactions On Engineering Management, Vol. 55, No. 2 , pp.316-328.

Huber, N., Michael, K., McCathiez, L.(2007), "Barriers to RFID Adoption in the Supply Chain", Faculty of Informatics Papers,University of Wollongong Year, pp.1-6 .

IIE Solutions(2002), "Florida Airport Gets First RFID System".

Kourouthanassis, Panos E., Giaglis, George, M.(2005), "Embedding Technology In The Retail Arena", Consumer Driven Elecktronic Transformation, Doukidis G.J., Vrehopoulos A.P. (Ed.), Consumer Driven Electronic Transformation: Applying New Technologies to Enthuse Consumers and Transform the Supply Chain, Berlin, Springer, pp. 227-240.

Lee, In, Lee, Byoung-Chan(2010), “An Investment Evaluation Of Supply Chain RFID Technologies: A Normative Modeling Approach", International Journal of Production Economics.

Levy, M., Weitz, B.(2003), "Retailing Management”, Berlin-Heidelberg, McGraw-Hill.

Loebbecke, C.(2005), "RFID Technology and Applications in the Retail Supply Chain: The Early Metro Group Pilot", 18th Bled eConference eIntegration in Action, Bled, Slovenia.

McLeod, S.(2008), "Case Study Method in Psychology”, Research Method.

Ngai, E.W.T., Moon, Karen, K.L., Riggins, Frederick J., Yi, Candace Y.(2008), "RFID Research: An Academic Literature Review (1995-2005) And Future Research Directions”, Int. J. Production Economics 112, pp.510-520.

Öztayşi, B., Baysan, S.,Akpınar F.(2009),’Radio Frequency Identification (RFID) In Hospitality”, Tecnovation,29,pp.618-624.

Piramuthu, S.(2007), "Protocols For RFID Tag/Reader Authentication", Decision Support Systems 43, pp.897-914. 
Ravi, V., Raman, K., Mantrala, M. K.(2010), “Applications of Intelligent Technologies in Retail Marketing”, Krafft M., Mantrala M. K. (Ed.) Retailing in the 21st Century, (pp. 127-141), New York, Springer.

Roberts, C.M.(2006), “Radio Frequency Idenfication (RFID)”, Computers \& Security 25, pp.18-26.

Roh, J. J., Kunnathur, A., Tarafdar, M.(2009), "Classification Of RFID Adoption: An Expected Benefits Approach”, Information\&Management, 46, p.357-363.

Schneider, Karen G.,(2003), "RFID and Libraries: Both Sides of the Chip”, RFID and Libraries.doc, avaliable at :

http://www.ala.org/offices/sites/ala.org.offices/files/content/oif/ifissues/rfidbothsideschip.pdf(accesse d 12 October 2012)

Shahid, S.Md.(2005), "Use Of RFID Technology In Libraries: A New Approach To Circulation, Tracking, Inventorying, And Security Of Library Materials", Library Philosophy And Practice Vol. 8, No. 1 (Fall 2005).

Shoewu, O., Badejo, O.(2006), "Radio Frenquency Identification Technology:Development, Application, and Security Issues", The Pacific Journal of Science and Technology, Volume 7. Number 2.

Slettemeas, D.(2009), "RFID — the "Next Step" in Consumer-Product Relations or Orwellian Nightmare? Challenges for Research and Policy", J Consum Policy 32, pp.219-244.

Sumi, S., Kumar, J.(2007), “Application Of RFID Technology In Libraries”, 5th International CALIBER-2007, Panjab University, Chand,garh, 08-10 February.

Stake, Robert E.(1978), "The Case Study Method In Social Unquiry”, Educational Researcher Vol. 7, No. 2 (Feb., 1978), pp. 5-8.

Tajima, M.(2007), "Strategic Value Of RFID In Supply Chain Management”, Journal Of Purchasing \& Supply Management 13, pp.261-273.

Varma, A.K., Ahmed, M. Imtiaz(2006), "RFID Applications In Libraries”, 4th International Convention CALIBER-2006, Gulbarga, 2-4 February.

Vasishta, S. (2009), "Roadmap for RFID Implementation in Central Library", Infrastructure And Policy Issues, 302 Ical 2009 - Technology, Polıcy And Innovation.

Topaloğlu, A.(2011), “IRCICA Library UHF RFID Solutions”, Türk Kütüphaneciliği 25,1,(2011), pp.106-116.

Yu, Shien-Chiang(2007), "RFID Implementation and Benefits In Libraries", The Electronic Library, Vol.25, No.1.

Wu, N.C., Nystrom, M. A., Lin, T.R., Yu, H.C.(2006), “Challenges To Global RFID Adoption”, Technovation, 26, pp.1317-1323. 